Journal of Urban and Regional Analysis, vol. XI, 1, 2019, p. 87 - 102

\title{
EMPIRICAL ANALYSIS ON THE DETERMINANTS OF URBAN PARKS
}

\author{
Kenichi SHIMAMOTO \\ Konan University, Kobe, Japan
}

\begin{abstract}
Urban parks play an important role in enhancing the lifestyle of the community by providing functions which support the environment, safety, health and ell-being. This paper will examine what the determining factors are for the development of urban parks, taking into consideration the supply side and demand side factors and past conditions of urban parks. Japan prefecture level data between 2001 to 2014 will be applied to a panel data analysis. The results find that for the supply side factors, the share of gross production by the construction industry and the financial strength of the local government; and on the demand side factors, preference towards the environment, health and well-being, have impact on the urban park area per capita at a statistically significant level.
\end{abstract}

Key Words: urban parks, financial strength of local government, preference, share of gross production by construction industry.

\section{Introduction}

In recent years, with the growing awareness of the sustainable development concept, there is an increasing demand for the consideration of the environment, health and safety alongside economic development. Urban parks are considered to play an important role by providing such functions that support the environment, safety, health, recreation and landscape (Ministry of Land, Infrastructure, Transportation and Tourism - Japan 2018). These functions supported by urban parks are well documented. In their role as green space, they provide services as urban ecosystems which include human health and well-being benefits and ecological benefits (Tzoulas et al. 2007, Breuste et al. 2013, Sutton and Anderson 2016). Studies which focus on the health and recreation function that urban parks provide are extensive (Bedimo-Rung et al. 2005, Giles-Corti et al. 2005, Pretty et al. 2005, Maller et al. 2006, Cohen et al. 2007, Lee and Maheswaran 2011, Wolch et al. 2011). Akpinar et al. (2016) study the impact of urban green space has on mental and general health across the Washington State in the United States. This impact is also studied by Song et al. (2015), concerning the walks through urban parks in Chiba, Japan, while Takano et al. (2002) study the association with longevity. The relationship with mental health is examined in 9 cities in Sweden (Grahn and Stigsdotter 2010) and in Helsinki, Finland (Tyrväinen et al. 2014). The impact on obesity and stress is also examined for Denmark (Sick Nielsen and Bruun Hansen 2007). The association between the recreational physical activity and the access to urban green space is examined for Norwich in the United Kingdom (Hillsdon et al. 2006).

Urban parks have been observed to service the environment through the provision of cooler microclimates and the reduction of surface water runoff, which offers potential support for cities to adapt to climate change (Gill et al. 2007). For example, mitigating the heat island effects in the built environments (Vidrih and Medved 2013) are examined for the cities of Vancouver, Sacramento (Spronken-Smith and Oke 1998), Lisbon (Oliveira et al. 2011) and Nagoya (Hamada and Ohta 2010, Hamada et al. 2013). Other literatures related to the environment include research on the urban residents' preference to be in contact with nature including trees and sounds (Carles et al. 1999, Lee et al. 2008, Matsuoka and Kaplan 2008). Other functions supported by urban parks include safety, which has been studied especially in Asia in relation 
to urban parks' role to support disaster prevention and emergency evacuation (Amemiya 2003, Masuda 2003, Zhu et al. 2016). There is also research on the relationship between urban parks and communication in the community (Coley et al.1997, Kuo et al. 1998, Chiesura 2004, Walker 2004). The financial impacts of urban parks have been examined from a number of angles. There are studies on urban parks in relation to housing and land prices based on the hedonic pricing model for Castellón, Spain (Bengochea Morancho 2003), Boston (Tajima 2003), Aalborg, Denmark (Panduro and Lausted Veie 2013), Lodz, Poland (Czembrowski and Kronenberg 2016), Sapporo, Japan (Aikoh et al. 2008), and Tokyo (Komatsu 2008). The economic benefits of urban parks have also been examined based on the willingness to pay for park availability in Copenhagen (Panduro et al. 2018) and conservation in Spain (LópezMosquera et al. 2014).

Based on these necessities for urban parks such as their importance for public health, research has gone into reviewing the accessibility and how they may not be equitably distributed. They review the accessibility based on socio-demographics to understand any differences such as income or ethnicity (Byrne et al. 2009, Neckerman et al. 2009, McConnachie and Shackleton 2010, Wolch et al. 2014). Furthermore, access to green space such as urban parks is being recognized as an environmental justice issue (Dai 2011, Jennings et al. 2012).

Further to literatures on the role and impact of urban parks, usability has also been examined. For example, Byrne et al. (2009) find that accessibility is an important factor for the usage of urban parks. Giles-Corti et al. (2005) explain the impact that the distance to and the size of parks have on usage. Studies on the usability for parks in Japan also examine the distance and accessibility to the parks (Shimomura et al. 1995, Boku et al. 1998). In this way, the determining factors concerning the utilization of urban parks have been studied in past literatures. However, to the best of my knowledge, they do not cover the determining factors of the provision of urban parks. Hence, this paper will attempt to examine the determinants of the provision of urban parks to answer the question of how the development of urban parks are determined. Furthermore, it has been identified that the volume of public goods such as urban parks are determined by factors on both the supply side and the demand side. In other words, where the marginal cost on the supply side coincides with the marginal benefit on the demand side, it will provide the maximum net benefit to society and determine the supply of public goods $^{1}$. It also can be considered that the existing urban parks will influence the size of the current urban parks. For example, if there is a year with a greater number of urban parks created, then there may be restrictions in the following year or it may stimulate further development of urban parks. Hence, this paper will focus on the supply side and demand side factors in relation to the development of urban parks and the existing urban parks to examine the possible significant impacts that these factors may have on urban park development. Japan prefecture level data from 2001 to 2014 will be utilized in the panel data analysis.

The second section will explain the methodology and data applied to analyse the determining factors of the provision of urban parks. The third section explains the results and it provides discussions concerning the main observations. The fourth section, the conclusions, provides a summary and it suggests the policy implications drawn from the results in section three.

\section{Methodology}

Urban parks, as well as other public goods, are reliant on economic variables. Furthermore, the supply of public goods is considered to be determined by the marginal cost to the supply side and the marginal benefit to the demand side, which means that the urban park area per capita

1)Although a park cannot be considered a pure public good given that a problem of congestion can arise and it is not physically difficult to exclude people from it, this paper will refer to it as a public good (Del Saz Salazar and García Menendez 2007). 
could also be determined in this way. This paper will also assume in the model that the construction of past urban parks has influence over the construction of current urban parks. Taking these points into consideration, it would be appropriate to use a dynamic panel data for this analysis. In particular, this paper will attempt to apply the dynamic panel analysis using first -differences. The characteristic of this model is that if the regression is completed at the level, the lagged dependent variable will correlate with an error term from the individual effect and it will not achieve a consistent estimate. However, in the model, the dependent variable and the independent variable will take the difference and the generalized method of moments (GMM) will be applied as a solution. With the specification used in the dynamic panel data model, if a second-order serial correlation in disturbances term exists, then it will not be possible to apply it as an instrumental variable. Then, the GMM estimator will not be a consistent estimator and a bias will occur. Hence, the Arellano-Bond test will be applied and it will examine whether the null hypothesis, which is the non-existence of the second-order serial correlation in disturbances, is rejected (Kitamura 2005, Uchiyama 2007, Chigira et al. 2011). Before conducting the above analysis, when the panel data is non-stationary, there is the risk of the spurious regression and so the dependent variables and all other independent variables used are examined using the Im-Pesaran-Shin and Fisher type panel unit root test and the stationarity of the data will be confirmed.

Next, we will review the variables used in this paper to understand the possible determinants of establishing urban parks.

\section{State Dependence (Parkt-1)}

As explained in the previous section, there is the possibility of state dependence on the urban parks. In other words, the construction of past urban parks could impact the construction of current urban parks. This paper takes into consideration this factor in the model.

\section{Share of Gross Production by the Construction Industry $(C P)$}

To represent an influential factor on the supply side, the share of gross production by construction industry for each region is adopted as an independent variable. The main supplier of public goods such as urban parks are construction companies, so it can be considered that they will have some influence over the provision of urban parks. For example, if construction companies have equal preference and capability to supply all public goods, a larger share of construction companies would mean a relatively larger amount of supply. Hence, the cost of constructing urban parks would be lower which could lead to an increase in urban parks. However, if there is stronger preference and/or capability of providing roads and other public facilities as public goods, then the supply of urban parks could decrease. In this way, the sign of the share of gross production of the construction industry could be positive or negative against the urban park area per capita. The construction industry's share of gross production is determined by the share of gross production by the construction industry by prefecture.

\section{Financial Strength}

Another supply side factor adopted as an independent variable is the financial strength of the local government since the local government finances the provision of urban parks. The net balance ratio $(N B R)$ will be used as the indicator of financial strength. The higher the amount of the actual expenditure rate means a healthy and stable financial operation which could be considered to have the capacity to fund the provision of urban parks. However, a prefecture with a large and positive NBR may prioritize projects with an explicit and high return on investment. Hence, investment in areas that struggle to quantify the benefits such as urban parks may not be a priority. In other words, the sign of the independent variable could be positive or negative. Depending on the objective or size of the urban park, the responsibility is 
shared between the prefecture and municipality. Most small parks fall under the responsibility of the municipality, but a large park that covers the area outside of one municipality will fall under the prefecture. Hence, the NBR is employed by calculating the weighted average of the $N B R$ for each prefecture and for each village/town/city with the corresponding expenditure.

\section{Preference and Prioritization of Urban Parks}

The provision of urban parks can also be influenced by demand. As mentioned in the earlier section, urban parks can have various positive effects on the environment, health, well-being and safety. This paper will examine how the demand of such functions that the urban parks provide can influence the development of urban parks. The prefecture level data that will be used as proxies to measure the demand of these functions are the municipal solid waste per capita, the number of hospitals per capita and the number of new subscriptions to fire insurance per capita.

The high production of municipal solid waste per capita (WASTE) could impact the ecosystem and create environmental issues such as dioxin from waste incineration and health concerns such as endocrine disruptor. Hence, a strong interest over the environment, health and wellbeing could lead to a demand of urban parks that can provide a positive impact in these areas. Thus, a positive sign can be expected from the independent variables.

Next, concerning the number of hospitals per capita for each prefecture (MED), a high MED could imply a high interest in health issues. A health-conscious prefecture could lead to a demand in the development of urban parks that could have a positive impact on health and well -being. On the other hand, the high penetration of hospitals could reduce the value of urban parks that support a healthy lifestyle and, as a result, the provision of urban parks could be limited. In other words, hospitals and urban parks could be in a substitute relationship. Therefore, the independent variable could show a positive or negative sign.

Concerning the number of new fire insurance subscribers per capita by prefecture (FIS), a larger number of subscribers could be considered as a higher interest in disaster prevention, safety concerns and well-being. Hence, this could lead to a stronger demand for urban parks which perform functions to support safety, disaster prevention and well-being. However, a large FIS could also weaken the need of such functions that urban parks provide and lead to a limited provision of urban parks. Like the MED case, FIS could be in a substitute relationship with urban parks. Hence, both positive and negative signs may be present with this variable.

Urban parks are also considered to provide important functions to support culture and strengthen communities, but prefecture level data that can be used as a proxy could not be identified. Prefecture level data to directly represent the preference concerning the environment, health, well-being and safety does not exist to the best of my knowledge. Under these data restrictions, the three indicators identified above, WASTE, MED and FIS, will be applied as proxies for these preferences $(P R E)$ in the analysis. All the variables are expressed in natural logarithms. The applied area and period for these variables are the 47 prefectures of Japan (Appendix 1) between the fiscal years of 2001 to 2014 . The data sources for the variables are provided in Appendix 2.

The basic model concerning the determinants of the urban park area per capita is provided below:

$$
\Delta \operatorname{Park}_{i t}=\alpha+\delta \Delta \operatorname{Park}_{i t-1}+\beta_{1} \Delta C P R_{i t}+\beta_{2} \Delta N B R_{i t}+\beta_{3} \Delta P R E_{i t}+\gamma_{i}+\Delta \varepsilon_{i t}
$$

The basic model above, takes heteroskedasticity into consideration. $\gamma_{i}$ of equation (1) 
represents the individual effects, ${ }^{\varepsilon_{i t}}$ the effort term. $\Delta$ represents the first difference.

\section{Results and Discussion}

Before we examine the basic model, the panel unit root test will be conducted on the dependent variables and all independent variables to ensure that the data is stationary. The ImPesaran-Shin panel unit root test, which is based on the mean of the individual Dickey-Fuller tstatistics of each unit in the panel, and the Fisher-type test which conducts unit root tests for each panel individually, are conducted to confirm whether the first differences of the above variables are stationary. This examination is useful for general observation. In the results achieved from these examinations (Table 1, Table 2), the corresponding p-values are essentially zero, so the existence of the unit root for all dependent variables and independent variables are rejected and it confirms that the data overall are stationary. If the second-order serial correlation in disturbances exists, then it may not be possible to apply instrumental variables and bias will occur with the GMM estimates. Hence, the Arellano-Bond test is applied to examine whether the null hypothesis, which is the non-existence of the second-order serial correlation in disturbances, is rejected. As in the results in Table 3, the second-order serial correlation in disturbances is rejected. The results of this test confirm that the GMM estimates are consistent.

Table 1

Im-Pesaran-Shin Panel Unit Root Test on Dependent and Explanatory Variables

\begin{tabular}{l|l|l|l}
\hline Variables & & Statistics & p-value \\
\hline PARK & Z-t-tilde-bar & -14.1159 & 0.000 \\
\hline$C P$ & Z-t-tilde-bar & -10.2930 & 0.000 \\
\hline$N B R$ & Z-t-tilde-bar & -12.1109 & 0.000 \\
\hline WASTE & Z-t-tilde-bar & -8.9873 & 0.000 \\
\hline$M E D$ & Z-t-tilde-bar & -10.4300 & 0.000 \\
\hline FIS & Z-t-tilde-bar & -9.4018 & 0.000 \\
\hline
\end{tabular}

Each independent variable will be examined based on these results. First, one of the supply side determinants, $C P$, indicates a positive sign in all models. This supports the suggestion that if the $C P$ with equal preference and capability to supply all public goods are greater, the contribution towards the supply of urban parks will be greater. However, only Model (2) achieves a statistically significant level. The other supply side determining factor, financial strength, the $N B R$, displays a significant negative sign for all models. This implies that when the $N B R$ is positive and greater, the prefecture may prioritize investment in areas other than urban parks. The investment may be in areas with a clearer return on investment which would be difficult to quantify with urban parks. 
Fisher Type Panel Unit Root Test on Dependent and Explanatory Variables

\begin{tabular}{|c|c|c|c|}
\hline Variables & & Statistics & p-value \\
\hline PARK & $\begin{array}{l}\text { Inverse chi-squared (94) } \quad \mathrm{P} \\
\text { Inverse normal } \quad \mathrm{Z} \\
\text { Inverse logit } \mathrm{t}(239) \quad \mathrm{L}^{*} \\
\text { Modified inverse chi-squared Pm }\end{array}$ & $\begin{array}{r}1426.2312 \\
-32.5630 \\
-57.4632 \\
97.1629\end{array}$ & $\begin{array}{l}0.000 \\
0.000 \\
0.000 \\
0.000\end{array}$ \\
\hline$\overline{C P}$ & $\begin{array}{l}\text { Inverse chi-squared (94) } P \\
\text { Inverse normal } \quad \mathrm{Z} \\
\text { Inverse logit t (239) } \mathrm{L}^{*} \\
\text { Modified inverse chi-squared Pm }\end{array}$ & $\begin{array}{r}529.1345 \\
-17.1402 \\
-21.1138 \\
31.7354\end{array}$ & $\begin{array}{l}0.000 \\
0.000 \\
0.000 \\
0.000\end{array}$ \\
\hline NBR & $\begin{array}{l}\text { Inverse chi-squared (94) } \quad \mathrm{P} \\
\text { Inverse normal } \quad \mathrm{Z} \\
\text { Inverse logit t (239) } \quad \mathrm{L}^{*} \\
\text { Modified inverse chi-squared Pm }\end{array}$ & $\begin{array}{r}852.5149 \\
-23.4001 \\
-34.2945 \\
55.3204\end{array}$ & $\begin{array}{l}0.000 \\
0.000 \\
0.000 \\
0.000\end{array}$ \\
\hline WASTE & $\begin{array}{l}\text { Inverse chi-squared (94) P } \\
\text { Inverse normal } \quad \mathrm{Z} \\
\text { Inverse logit t (239) } \quad \mathrm{L}^{*} \\
\text { Modified inverse chi-squared Pm }\end{array}$ & $\begin{array}{r}409.0198 \\
-13.5714 \\
-16.0958 \\
22.9752\end{array}$ & $\begin{array}{l}0.000 \\
0.000 \\
0.000 \\
0.000\end{array}$ \\
\hline$M E D$ & $\begin{array}{l}\text { Inverse chi-squared (94) } \mathrm{P} \\
\text { Inverse normal } \quad \mathrm{Z} \\
\text { Inverse logit t (239) } \quad \mathrm{L}^{*} \\
\text { Modified inverse chi-squared Pm }\end{array}$ & $\begin{array}{r}566.3459 \\
-17.3067 \\
-22.5318 \\
34.4494 \\
\end{array}$ & $\begin{array}{l}0.000 \\
0.000 \\
0.000 \\
0.000\end{array}$ \\
\hline FIS & $\begin{array}{l}\text { Inverse chi-squared (94) } P \\
\text { Inverse normal } \quad \mathrm{Z} \\
\text { Inverse logit } \mathrm{t}(239) \quad \mathrm{L}^{*} \\
\text { Modified inverse chi-squared Pm }\end{array}$ & $\begin{array}{r}336.9024 \\
-13.1034 \\
-13.4637 \\
17.7155\end{array}$ & $\begin{array}{l}0.000 \\
0.000 \\
0.000 \\
0.000\end{array}$ \\
\hline
\end{tabular}

Basic Models

Table 3

\begin{tabular}{l|ccc}
\hline \multirow{2}{*}{ Variables } & \multicolumn{3}{|c}{ Models } \\
\cline { 2 - 4 } PARKt-1 & (1) & (2) & (3) \\
& 0.0186 & 0.0728 & 0.1080 \\
CP & $(0.0896)$ & $(0.0789)$ & $(0.0770)$ \\
\hline NBR & 0.0142 & $0.0181^{*}$ & 0.0176 \\
& $(0.0100)$ & $(0.0106)$ & $(0.0113)$ \\
\hline WASTE & $-0.0165^{* *}$ & $-0.0242^{* * *}$ & $-0.0291^{* * *}$ \\
& $(0.0081)$ & $(0.0080)$ & $(0.0089)$ \\
\hline MED & $0.1130^{* * *}$ & & \\
& $(0.0359)$ & & \\
\hline FIS & \multicolumn{3}{|c}{$0.0969^{*}$} \\
& & $(0.0548)$ & -0.0004 \\
\hline
\end{tabular}


Empirical Analysis on the Determinants of Urban Parks

\begin{tabular}{l|ccc}
\hline Constant & $\begin{array}{c}0.1790^{* * *} \\
(0.0511)\end{array}$ & $\begin{array}{c}0.9990^{*} \\
(0.5130)\end{array}$ & $\begin{array}{c}0.0803 \\
(0.0523)\end{array}$ \\
\hline Wald test & 33.9800 & 20.1800 & 16.5000 \\
& $(0.0000)$ & $(0.0050)$ & $(0.0240)$ \\
\hline Arellano-Bond test(2) & -0.5988 & -0.2775 & 0.0431 \\
& $(0.5493)$ & $(0.7814)$ & $(0.9657)$ \\
\hline Observations & 564 & 564 & 564 \\
\hline
\end{tabular}

Robust standard errors in parentheses

${ }^{* * *} p<0.01,{ }^{* *} p<0.05,{ }^{*} p<0.1$

Model (1): WASTE is the proxy for PRE

Model (2): MED is the proxy for PRE

Model (3): FIS is the proxy for PRE

Concerning the demand side determinant, WASTE, which is one of the proxies to represent the preference concerning the environment and health which are supported by urban parks, indicates a significant positive sign. This suggests that higher WASTE may provide greater exposure to environmental and health issues, creating a much stronger demand for urban parks which support these needs. Next, the MED, which is applied as a proxy for healthconsciousness, shows a significant positive sign. As mentioned in the previous section, this could suggest that the regions with greater MED could be exposed to greater health issues and a greater awareness of the function that urban parks play in supporting healthy lifestyles and as a result have greater urban parks. Concerning the FIS, the proxy applied to represent the preference concerning disaster prevention, safety and well-being, shows that prefectures with high FIS have greater urban park area per capita. The greater awareness of safety and emergency may be reflected in the development of urban parks. Like the MED case, FIS and urban parks are not found to be in a substitute relationship as it was originally anticipated. However, there is a need to note that the results in Model (3) do not meet a significant standard. The size of the urban parks a year prior, which represents the previous state, displays positive impacts in all the models, but it does not reach a significant standard.

All the independent variables have been treated as exogenous variables in the analysis, but there is the need to consider the possibility of the variables being endogenous. If we examine this possibility for each variable, concerning the $N B R$, if the provision of urban parks reduces the available commercial, industrial or residential space, effecting the tax revenue, this would impact the NBR. Concerning the $C P$, the provision of urban parks, in turn, may stimulate the investment in public works and it may increase the $C P$. The provision of urban parks could also increase the awareness of environment and health, which could in turn reduce WASTE, which is applied as a proxy for environment, health, well-being and safety. A similar impact may occur with the other proxies, MED and FIS. In this way, the independent variable may not only be a determining factor for the size of urban parks, but also the result, which would support the possibility of endogeneity. Hence, the endogeneity will need to be considered when examining the relationship between urban parks and the independent variables.

As in the previous case where independent variables were treated as exogenous variables, the Arellano-Bond test rejected the second-order serial correlation in disturbances and all the models are accepted by model specification. Hence, we will first examine the case where one of the independent variables is endogenous.

As indicated in Table 4, the signs in all models are the same as in the case where all 
Models with One Endogenous Variable

\begin{tabular}{|c|c|c|c|c|c|c|c|c|c|}
\hline & \multicolumn{9}{|c|}{ Model } \\
\hline & (4) & (5) & (6) & (7) & (8) & (9) & (10) & $(11)$ & $(12)$ \\
\hline \multirow{4}{*}{$\frac{P A R K t-1}{C P}$} & 0.0356 & 0.0554 & 0.0791 & 0.0195 & 0.0546 & 0.0978 & \begin{tabular}{|l|l|}
0.02877 \\
\end{tabular} & 0.0460 & 0.0653 \\
\hline & $(0.0761)$ & $(0.0738)$ & $(0.0739)$ & $(0.0946)$ & $(0.0873)$ & $(0.0873)$ & $(0.0678)$ & $(0.0734)$ & $(0.0704)$ \\
\hline & 0.0138 & 0.0181 & $0.0234^{* *}$ & 0.0157 & $0.0215^{* *}$ & $0.0243^{\star \star}$ & $0.0171^{*}$ & 0.0148 & $0.0264^{* * *}$ \\
\hline & $(0.009)$ & $(0.011)$ & $(0.0113)$ & $(0.0102)$ & $(0.0108)$ & $(0.0110)$ & $(0.0094)$ & $(0.0097)$ & $(0.0096)$ \\
\hline \multirow{4}{*}{$\frac{N B R}{\text { WASTE }}$} & $-0.0154^{*}$ & $-0.0256^{* * *}$ & $-0.0351^{* * *}$ & -0.0095 & -0.0144 & -0.0250 & $-0.0205^{\star \star}$ & $-0.0157^{\star \star}$ & $-0.0368^{* * *}$ \\
\hline & $(0.0092)$ & $(0.0084)$ & $(0.0108)$ & $(0.0136)$ & $(0.0156)$ & $(0.0173)$ & \begin{tabular}{|l|}
$(0.0086)$ \\
\end{tabular} & $(0.0077)$ & $(0.0096)$ \\
\hline & $0.1030^{* * *}$ & & & $0.1220^{* * *}$ & & & $0.0911^{* \star *}$ & & \\
\hline & $(0.0313)$ & & & $(0.0330)$ & & & $(0.0199)$ & & \\
\hline \multirow[t]{2}{*}{$M E D$} & & $0.1170^{\star \star *}$ & & & $0.1580^{* * *}$ & & & $0.2110^{\star * \star}$ & \\
\hline & & $(0.0448)$ & & & $(0.0544)$ & & & $(0.0488)$ & \\
\hline \multirow[b]{2}{*}{ FIS } & & & 0.0012 & & & 0.0014 & & & 0.0038 \\
\hline & & & $(0.0075)$ & & & $(0.0073)$ & & & $(0.0071)$ \\
\hline \multirow[t]{2}{*}{ Constant } & $0.1670^{* * *}$ & $1.1950^{* * *}$ & $0.1070^{* *}$ & $0.1880^{* * *}$ & $1.5810^{* * *}$ & $0.1040^{* *}$ & $0.1670^{* \star \star}$ & $2.0660^{\star \star \star}$ & $0.1270^{* * \star}$ \\
\hline & $(0.0440)$ & $(0.4160)$ & $(0.0514)$ & $(0.0492)$ & $(0.5030)$ & $(0.0482)$ & $(0.0300)$ & $(0.4570)$ & $(0.0397)$ \\
\hline \multirow{2}{*}{$\begin{array}{l}\text { Wald test } \\
\text { (Prob. > } \\
\text { chi2) } \\
\end{array}$} & 33.2800 & 23.2100 & 17.0500 & 30.8700 & 23.0800 & 12.2800 & 45.7 & 35.4700 & 23.7100 \\
\hline & $(0.0000)$ & $(0.0001)$ & $(0.0019)$ & $(0.0000)$ & $(0.0001)$ & $(0.0154)$ & $(0.0000)$ & $(0.0000)$ & $(0.0001)$ \\
\hline $\begin{array}{l}\text { A-B test } \\
(2)^{\star \star \star \star}\end{array}$ & -0.4647 & -0.4126 & -0.2631 & -0.5697 & -0.4015 & -0.0559 & -0.6277 & -0.4453 & -0.4168 \\
\hline $\begin{array}{l}\text { (Prob. }> \\
\mathrm{z} \text { ) }\end{array}$ & $(0.6422)$ & (0.6799) & $(0.7925)$ & $(0.5689)$ & (0.6881) & $(0.9554)$ & $(0.5302)$ & $(0.6561)$ & $(0.6768)$ \\
\hline $\mathrm{N}^{* * * * *}$ & 564 & 564 & 564 & 564 & 564 & 564 & 564 & 564 & 564 \\
\hline
\end{tabular}

Robust standard errors in parentheses

${ }^{* * *} p<0.01,{ }^{* *} p<0.05,{ }^{*} p<0.1$

$* * * *$ Arellano-Bond test $(2)$

$* * * * *$ number of observations

Model (4): only CP is endogenous; WASTE is the proxy for PRE

Model (5): only CP is endogenous; MED is the proxy for PRE

Model (6): only CP is endogenous FIS is the proxy for PRE

Model (7): only NBR is endogenous; WASTE is the proxy for PRE

Model (8): only NBR is endogenous; MED is the proxy for PRE

Model (9): only NBR is endogenous; FIS is the proxy for PRE

Model (10): only WASTE is endogenous

Model (11): only MED is endogenous

Model (12): only FIS is endogenous

independent variables were applied as exogenous variables. In particular, significant positive signs are identified in Models (6), (8), (9), (10) and (12) for the supply side factor, $C P$. Models (4), (5), (6), (10), (11) and (12) confirm significant negative results for NBR which are consistent with the previous results where all independent variables are treated as exogenous. Concerning the demand side factors, the results for WASTE show significant positive results against the urban park area per capita in Models (4), (7) and (10); MED results display significant positive coefficients in Models (5), (8) and (11); and the FIS results are positive signs, but they do not meet a significant level as in the previous case with the exogenous variables. But, the results for the area size of urban parks one year earlier, which describe the 
previous situations, indicate that all models show positive impacts, but they do not reach significant levels, which is consistent with the exogenous variable case.

Next, we will examine the case where there are 2 endogenous variables. The results in Table 5 are consistent with the previous case where there was one endogenous variable. Concerning the supply side determinants, Models (13), (14), (15), (16), (18), (19) and (21) find $C P$ showing significant positive results and NBR displaying significant negative results in Models (16), (17), (18) and (21). On the demand side, the results for WASTE in Models (13), (16) and (19) are significantly positive as well as the results for MED in Models (14), (17) and

Models with Two Endogenous Variables

Table 5

\begin{tabular}{|c|c|c|c|c|c|c|c|c|c|}
\hline & \multicolumn{9}{|c|}{ Model } \\
\hline & (13) & (14) & (15) & (16) & (17) & (18) & (19) & (20) & (21) \\
\hline \multirow[t]{2}{*}{ PARKt-1 } & 0.0415 & 0.0551 & 0.0857 & 0.0437 & 0.0467 & 0.0757 & 0.0291 & 0.0452 & 0.0714 \\
\hline & $(0.0758)$ & $(0.0734)$ & $(0.0772)$ & $(0.0713)$ & $(0.0749)$ & $(0.0723)$ & $(0.0682)$ & $(0.0734)$ & $(0.0757)$ \\
\hline \multirow[t]{2}{*}{$C P$} & $0.0162^{\star}$ & $0.0200^{\star \star}$ & $0.0284^{\star \star \star}$ & $0.0206^{\star \star}$ & 0.0152 & $0.0274^{\star \star \star}$ & $0.0175^{\star}$ & 0.0148 & $0.0274^{\star \star \star}$ \\
\hline & $(0.0087)$ & $(0.0102)$ & $(0.0096)$ & $(0.0084)$ & $(0.0096)$ & $(0.0096)$ & $(0.0094)$ & $(0.0095)$ & $(0.0094)$ \\
\hline \multirow[t]{2}{*}{ NBR } & -0.0044 & -0.0121 & -0.0258 & $-0.0156^{\star}$ & $-0.0153^{\star}$ & $-0.0311^{\star \star \star}$ & -0.0122 & -0.0035 & $-0.0308^{*}$ \\
\hline & $(0.0087)$ & $(0.0124)$ & $(0.0159)$ & $(0.0085)$ & $(0.0087)$ & $(0.0110)$ & $(0.0110)$ & $(0.0092)$ & $(0.0168)$ \\
\hline \multirow[t]{2}{*}{ WASTE } & $0.1130^{\star \star \star}$ & & & $0.0817^{\star \star \star}$ & & & $0.1020^{\star \star \star}$ & & \\
\hline & $(0.0301)$ & & & $(0.0183)$ & & & $(0.0194)$ & & \\
\hline \multirow[t]{2}{*}{$M E D$} & & $0.1660^{\star \star \star}$ & & & $0.2020^{\star \star \star}$ & & & $0.2620^{\star \star \star}$ & \\
\hline & & $(0.0494)$ & & & $(0.0488)$ & & & $(0.0547)$ & \\
\hline \multirow[t]{2}{*}{ FIS } & & & 0.0039 & & & 0.0004 & & & 0.0044 \\
\hline & & & $(0.0072)$ & & & $(0.0073)$ & & & $(0.0076)$ \\
\hline \multirow[t]{2}{*}{ Constant } & $0.1770^{\star \star \star}$ & $1.6530^{\star \star \star}$ & $0.1260^{\star \star \star}$ & $0.1650^{\star \star \star}$ & $1.9830^{\star \star \star}$ & $0.1130^{\star \star}$ & $0.1750^{\star \star \star}$ & $2.5410^{\star \star \star}$ & $0.1280^{\star \star \star}$ \\
\hline & $(0.0409)$ & $(0.4540)$ & $(0.0426)$ & $(0.0297)$ & $(0.4560)$ & $(0.0441)$ & $(0.0288)$ & $(0.5090)$ & $(0.0394)$ \\
\hline Wald test & 46.3000 & 34.6500 & 19.3700 & 51.6400 & 36.2600 & 17.3500 & 31.8900 & 32.9300 & 18.0900 \\
\hline $\begin{array}{l}\text { (Prob. > } \\
\text { chi2) }\end{array}$ & $(0.0000)$ & $(0.0000)$ & $(0.0007)$ & $(0.0000)$ & $(0.0000)$ & $(0.0017)$ & $(0.0000)$ & $(0.0000)$ & $(0.0012)$ \\
\hline $\begin{array}{l}\text { A-B test } \\
(2)^{\star \star \star \star \star}\end{array}$ & -0.4515 & -0.4314 & -0.2992 & -0.5941 & -0.3943 & -0.3344 & -0.3793 & -0.3635 & -0.1715 \\
\hline (Prob. > z) & $(0.6516)$ & $(0.6662)$ & $(0.7648)$ & $(0.5525)$ & $(0.6934)$ & $(0.7381)$ & $(0.7045)$ & $(0.7163)$ & $(0.8638)$ \\
\hline $\mathrm{N}^{\star \star \star \star \star \star}$ & 564 & 564 & 564 & 564 & 564 & 564 & 564 & 564 & 564 \\
\hline
\end{tabular}

Robust standard errors in parentheses

${ }^{* * *} p<0.01,{ }^{* *} p<0.05,{ }^{*} p<0.1$

$* * * \star$ Arellano-Bond test (2)

$\star * * * *$ number of observations

Model (13): CP and NBR are endogenous; WASTE is the proxy for PRE

Model (14): CP and NBR are endogenous; MED is the proxy for PRE

Model (15): CP and NBR are endogenous; FIS is the proxy for PRE

Model (16): CP and WASTE are endogenous

Model (17): CP and MED are endogenous

Model (18): CP and FIS are endogenous

Model (19): NBR and WASTE is endogenous

Model (20): NBR and MED is endogenous

Model (21): NBR and FIS is endogenous 
(20). However, the signs for FIS show a consistent trend, but not at a significant level. As in the previous cases, the previous year shows a positive relationship against the current urban park area per capita in all models, but not at a significant level.

Finally, we will observe the case where all the independent variables are exogenous. As displayed in Table 6 , the results in all models support the same sign as in the previous exogenous cases. Concerning the supply side factor, in Model (22) and (24), the CP show positive and significant results and the NBR displays negative and significant results. On the demand side, WASTE displays a positive and significant result in Model (22) and the MED shows a significant positive impact in Model (23). FIS, though showing a consistent sign, is not at a statistically significant level. The urban park area in the previous year compared to the current year shows a positive relationship in all models, but not at a significant level.

From these results, we learn that, in all reviewed cases which include independent variables

Models with All Endogenous Variable

Table 6

\begin{tabular}{|l|c|c|c|}
\hline & \multicolumn{3}{|c|}{ Model } \\
\cline { 2 - 4 } Variables & $(\mathbf{2 2})$ & $(\mathbf{2 3})$ & $(\mathbf{2 4})$ \\
\hline PARKt-1 & 0.0436 & 0.0444 & 0.0782 \\
\hline CP & $(0.0717)$ & $(0.0748)$ & $(0.0765)$ \\
\hline NBR & $0.0208^{\star \star}$ & 0.0149 & $0.0273^{\star \star}$ \\
& $(0.0085)$ & $(0.0094)$ & $(0.0097)$ \\
\hline WASTE & -0.0101 & -0.0032 & $-0.0279^{\star}$ \\
\hline MED & $(0.0098)$ & $(0.0083)$ & $(0.0164)$ \\
\hline FIS & $0.0880^{\star \star \star}$ & & \\
& $(0.0169)$ & & \\
\hline Constant & & $0.2550^{\star \star \star}$ & \\
& & $(0.0533)$ & \\
\hline Wald test & & & 0.0009 \\
(Prob. > chi2) & & & $(0.0076)$ \\
\hline Arellano-Bond test(2) & -0.4287 & -0.3938 & -0.2589 \\
\hline (Prob. > z) & $(0.6682)$ & $(0.6937)$ & $(0.7957)$ \\
\hline Observations & 564 & 564 & 564 \\
\hline
\end{tabular}

Robust standard errors in parentheses

${ }^{* * *} p<0.01,{ }^{* *} p<0.05,{ }^{*} p<0.1$

Model (22): CP, NBR and WASTE is endogenous

Model (23): CP, NBR and MED is endogenous

Model (24): CP, NBR and FIS is endogenous

treated as exogenous and endogenous, for the supply side determinants, $C P$ displays significant positive results and the NBR shows significant negative results in most of the models. Considering that there is limited past research on the supply side factors that impact the provision of urban parks, the significant results concerning the impact that the construction industry has on urban parks is a unique find. Concerning economic influences, this paper has 
reviewed past literatures on the impact that urban parks have on housing prices, and they identified positive impacts (Bengochea Morancho 2003, Tajima 2003, Panduro and Lausted Veie 2013, Czembrowski and Kronenberg 2016). Literatures which studied the impact of urban parks in Japan on land prices were also positive (Aikoh et al. 2008, Komatsu 2008). However, these past literatures did not cover the impacts that the financial strength of the local governments have on the provision of urban parks which has been identified to have no positive impact on the development of urban parks in this study.

Concerning the demand side determinants, WASTE, the proxy for the environment and health which are functions supported by urban parks, shows significant positive results. The literatures reviewed previously on the impact that urban parks have on the environment also indicated positive impacts (Spronken-Smith and Oke 1998, Carles et al. 1999, Lee et al. 2008, Matsuoka and Kaplan 2008, Oliveira et al. 2011). Studies on urban parks in Japan also found positive impacts on the environment, through their cooling effects to counter global warming (Hamada and Ohta 2010, Hamada et al. 2013). The higher WASTE may provide greater exposure to environmental and health issues, creating a much stronger demand for urban parks, which in these past studies confirm a positive impact on the environment. The MED, the proxy employed for health consciousness, displays significant positive impacts on the urban park area per capita in all models. The literature reviewed in this paper on the impact of urban parks on health also indicated positive results including the studies on Japan (Takano et al. 2002, Sick Nielsen and Bruun Hansen 2007, Grahn and Stigsdotter 2010, Tyrväinen et al. 2014, Song et al. 2015, Akpinar et al. 2016). This suggests that health consciousness influences the development of urban parks and, in return, it has a positive impact on health and well-being.

Concerning the size of urban parks in the previous year, which describes the previous state, it was identified to have a positive relationship with urban park area per capita, but not at a statistically significant level.

Since the dependent variable and each independent variable are expressed in natural logarithms, the coefficient for each independent variable represents elasticity. Hence, the strength of the elasticity against the dependent variable, urban park area per capita for each independent variable can be compared. By observing the significant coefficients, we learn that on the supply side, the $C P$ indicates an elasticity between the range of 0.0162 to 0.0284 and the NBR, the financial indicator, a value of -0.0153 to -0.0368 . On the demand side, WASTE indicates 0.0817 to 0.122 and MED values between 0.0969 and 0.262 . Thus, the results indicate that the demand side factors have relatively greater elasticity compared to the supply side factors.

\section{Conclusions}

With the growing awareness on sustainable development, the occurrence of natural disasters and the increasing health consciousness, it is important to understand the determinants of the development of urban parks which are considered to have functions to support the environment, the health, safety and well-being of the population. The volume of public goods which include urban parks are determined by the supply side and demand side factors. This paper focuses on the supply side and demand side factors and the situation of past urban parks to observe if they have any significant impact on the development of urban parks. It effectively applies Japan prefecture level data from 2001 to 2014 in the panel data analysis.

The results find cases where the supply side factors, such as the $C P$ and $N B R$, and the demand side factors, which include preference concerning the environment, health and wellbeing, have statistically significant impact on the urban park area per capita. These results provide some policy implications. First, in a number of models, the financial strength indicator, $N B R$, displays a significant negative impact on the development of urban parks. This may be 
due to prefectures preferring to focus on areas with a clear return on investment. Hence, the development of urban parks with limited ability to quantify the benefits may become a lower priority. However, this may mean that if the benefits of urban parks could be quantified, under a solid financial operation, the cost of these benefits could be incorporated, leading to a more active development of urban parks. In this way, urban parks, a public good with limited ability to be valued in the market, could benefit from further analysis concerning the application and improvement of a number of evaluation methods such as the revealed preference approach and the stated preference approach in order to quantify the important functions which urban parks provide.

One of the main players in the development of urban parks is the construction industry. The $C P$ impact on the urban park area per capita is a significant positive one. However, the construction companies may focus heavily on construction projects other than urban parks such as economic infrastructure. Therefore, in order to avoid a bias towards economic infrastructure and to achieve a sustainable well-balanced supply of public goods, it may be necessary to educate the market and to introduce incentives.

The WASTE indicates some significantly positive impacts on urban park area per capita which has positive influence on the environment and health. In all models, the MED suggests healthconsciousness to have a significant impact on the development of urban parks. These results suggest that a strategy and execution plan on the development of the environment and health may be required to facilitate the development of urban parks. This could create the need for education, development and reinforcement of regulations. It may also indicate a need for urban parks to be designed and for facilities to be provided in order to support the environment and a healthy life-style. There may be cases where the preference for other goods and services could be in a substitute relationship with the preference for urban parks, so in order to facilitate the development of urban parks, it may be necessary to provide goods and services which are in a complementary relationship with urban parks.

The consideration of these suggested policies could facilitate the development of urban parks which provide important functions to the well-being of society through the improvement of the environment and the safety and health of the population. In turn, this could lead to the progress towards a sustainable society. 


\section{Prefectures of Japan}

Appendix 1

1 Hokkaido, 2 Aomori, 3 Iwate, 4 Miyagi, 5 Akita, 6 Yamagata, 7 Fukushima, 8 Ibaraki, 9 Tochigi, 10 Gunma, 11 Saitama, 12 Chiba, 13 Tokyo, 14 Kanagawa, 15 Niigata, 16 Toyama, 17 Ishikawa, 18 Fukui, 19 Yamanashi, 20 Nagano, 21 Gifu, 22 Shizuoka, 23 Aichi, 24 Mie, 25 Shiga, 26 Kyoto, 27 Osaka, 28 Hyogo, 29 Nara, 30 Wakayama, 31 Tottori, 32 Shimane, 33 Okayama, 34 Hiroshima, 35 Yamaguchi, 36 Tokushima, 37 Kagawa, 38 Ehime, 39 Kochi, 40 Fukuoka, 41 Saga, 42 Nagasaki, 43 Kumamoto, 44 Oita, 45 Miyazaki, 46 Kagoshima, 47 Okinawa

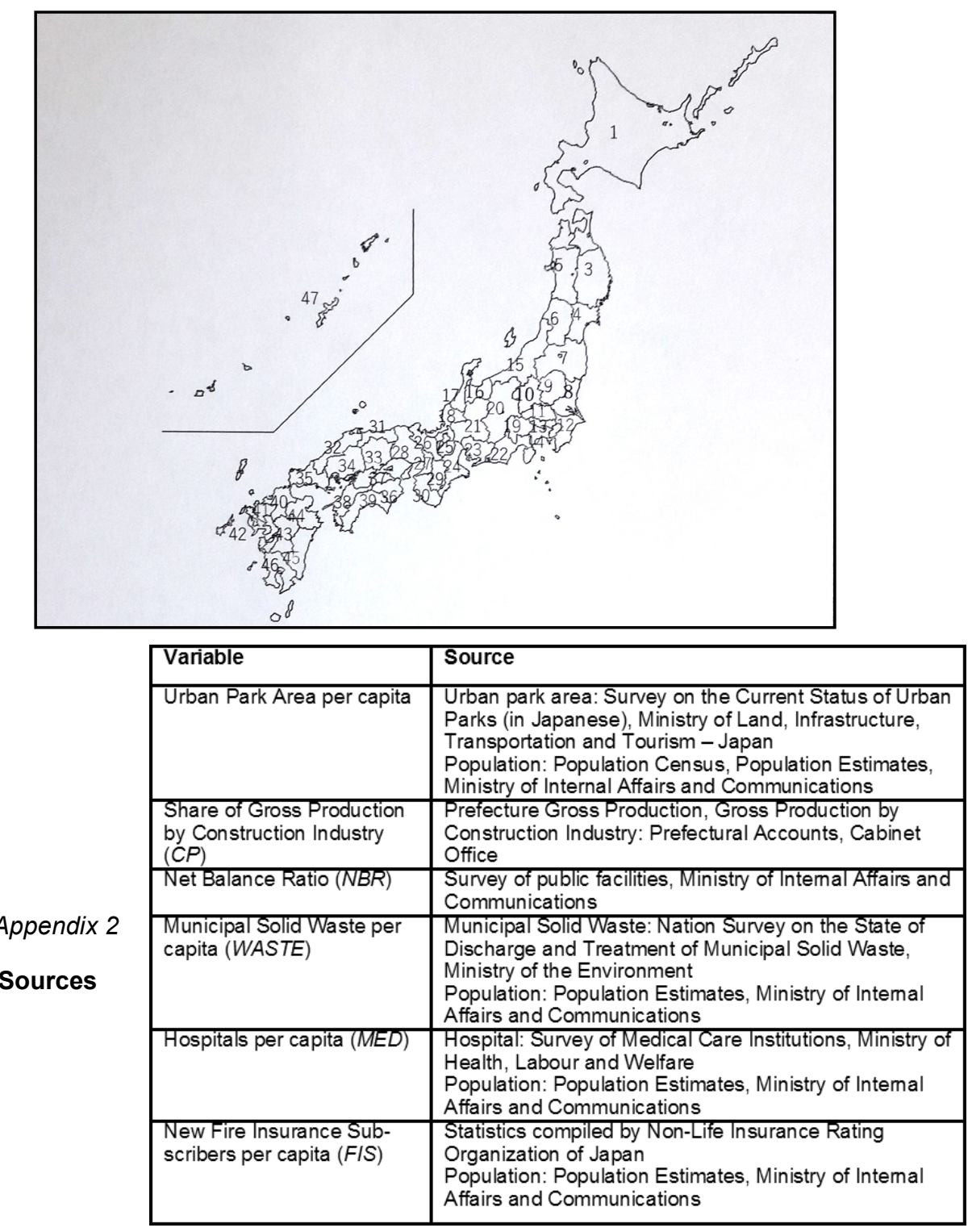




\section{References}

AIKOH T., SAKIYAMA N., SHOJI Y. (2008), Analysis of economic effect of green spaces on land price in residential areas by hedonic approach, Journal of The Japanese Institute of Landscape Architecture 71 (5), 727-730.

AMEMIYA M. (2003), A review of progress in park and open space safety research: towards a new planning theory, Journal of The Japanese Institute of Landscape Architecture 66 (3), 185-190.

AKPINAR A., BARBOSA-LEIKER C., BROOKS K. R. (2016), Do green space matter? Exploring relationships between green space type and health indicators, Urban Forestry \& Urban Greening 20, 407-418.

BEDIMO-RUNG A., MOWEN A. J., COHEN D. A. (2005), The significance of parks to physical activity and public health: A conceptual model, American Journal of Preventive Medicine 28 (2), 159-168.

BENGOCHEA MORANCHO A. (2003), A hedonic valuation of urban green areas, Landscape and Urban Planning 66 (1), 35-41.

BOKU E., TASHIRO Y., KINOSHITA T. (1998), A study on relation between the characteristics of park use of aged people and their access distance, Journal of The Japanese Institute of Landscape Architecture 65 (1), 781-784

BREUSTE J., QURESHI S., LI J. (2013), Scaling down the ecosystem services at local level for urban parks of three megacities, Hercynia N. F. 46, 1-20.

BYRNE J., WOLCH J., ZHANG J. (2009), Planning for environmental justice in urban national park, Journal of Environmental Planning and Management 52 (3), 365-392.

CARLES J. L., LÓPEZ BARRIO I., DE LUCIO J. V. (1999), Sound influence on landscape values, Landscape and Urban Planning 43 (4), 191-200.

CHIESURA A. (2004), The role of urban parks for the sustainable city, Landscape and Urban Planning 68 (1), 129-138.

CHIGIRA H., HAYKAWA K., YAMOAMOTO T. (2011), Dogakuteki panel data bunseki (Dynamic panel data analysis), Chisen Shokan, Tokyo.

COHEN D. A., MCKENZIE T. L., SEHGAL A., WILLIAMSON S., GOLINELLI D., LURIE

N. (2007), Contribution of Public Parks to Physical Activity, American Journal of Public Health 97 (3), 509-514.

COLEY R. L., SULLIVAN W. C., KUO F. E. (1997), Where Does Community Grow? The Social Context Created by Nature in Urban Public Housing, Environment and Behavior 29 (4), 468-494.

CZEMBROWSKI P., KRONENBERG J. (2016), Hedonic pricing and different urban green space types and sizes: Insights into the discussion on valuing ecosystem services, Landscape and Urban Planning 146, 11-19.

DAI D. (2011), Racial/ethnic and socioeconomic disparities in urban green space accessibility: Where to intervene?, Landscape and Urban Planning 102 (4), 234-244.

DEL SAZ SALAZAR S., GARCÍA MENENDEZ L. (2007), Estimating the non-market benefits of an urban park: Does proximity matter?, Land Use Policy 24 (1), 296-305.

GILES-CORTI B., BROOMHALL M. H., KNUIMAN M., COLLINS C., DOUGLAS K., NG K., LANGE A., DONOVAN R. J. (2005), Increasing walking: How important is distance to, attractiveness, and size of public open space?, American Journal of Preventative Medicine 28 (2), 169-176.

GILL S. E., HANDLEY J. F., ENNOS A. R., PAULEIT S. (2007), Adapting cities for climate change: the role of the green infrastructure, Built Environment 33 (1), 115-133.

GRAHN P., STIGSDOTTER U. K. (2010), The relation between perceived sensory dimensions of urban green space and stress restoration, Landscape and Urban Planning 94 (34), 264-275.

HAMADA S., OHTA T. (2010), Seasonal variations in the cooling effect of urban green areas on surrounding urban areas, Urban Forestry \& Urban Greening 9 (1), 15-24. 
HAMADA S., TANAKA T., OHTA T. (2013), Impacts of land use and topography on the cooling effect of green areas on surrounding urban areas, Urban Forestry \& Urban Greening 12 (4), 426-434.

HILLSDON M., PANTER J., FOSTER C., JONES A. (2006), The relationship between access and quality of urban green space with population physical activity, Public Health 120 (12), 1127-1132.

JENNINGS V., GAITHER C. J., SCHULTERBRANDT GRAGG R. S. (2012), Promoting Environmental Justice Through Urban Green Space Access: A Synopsis, Environmental Justice 5 (1), 1-7.

KITAMURA Y. (2005), Panel data analysis, Iwanami Shoten, Tokyo.

KOMATSU H. (2008), A study on land pricing structure of urban public parks in commercial areas, The Japanese Journal of Real Estate Sciences 21 (4), 103-114.

KUO F. E., SULLIVAN W. C., COLEY R. L., BRUNSON L. (1998), Fertile Ground for Community: Inner-City Neighborhood Common Spaces, American Journal of Community Psychology 26 (6), 823-851.

LEE A. C., MAHESWARAN R. (2011), The health benefits of urban green spaces: a review of the evidence, Journal of Public Health 33 (2), 212-222.

LEE S.-W., ELLIS C. D., KWEON B.-S., HONG S.-K. (2008), Relationship between landscape structure and neighborhood satisfaction in urbanized areas, Landscape and Urban Planning 85 (1), 60-70.

LÓPEZ-MOSQUERA N., GARCÍA T., BARRENA R. (2014), An extension of the Theory of Planned Behavior to predict willingness to pay for the conservation of an urban park, Journal of Environmental Management 135, 91-99.

MALLER C., TOWNSEND M., PRYOR A., BROWN P., ST LEGER L. (2006), Healthy nature healthy people: 'contact with nature' as an upstream health promotion intervention for populations, Health Promotion International 21 (1), 45-54.

MASUDA N. (2003), Urban park planning from the point of view of the safety and secure urban environment, Landscape Research Japan Online 66 (3), 180-184.

MATSUOKA R. H., KAPLAN R. (2008), People needs in the urban landscape: Analysis of Landscape and Urban Planning Contributions, Landscape and Urban Planning 84 (1), 7-19.

MCCONNACHIE M. M., SHACKLETON C. M. (2010), Public green space inequality in small towns in South Africa, Habitat International 34 (2), 244-248.

MINISTRY OF LAND, INFRASTRUCTURE, TRANSPORTATION AND TOURISM JAPAN (2018), Toshi-koen no yakuwari (The Role of Urban Parks), Retrieved from: http:// www.mlit.go.jp.

NECKERMAN K. M., LOVASI G. S., DAVIES S., PURCIEL M., QUINN J., FEDER E., RAGHUNATH N., WASSERMAN B., RUNDLE A. (2009), Disparities in Urban Neighborhood Conditions: Evidence from GIS Measure and Field Observation in New York City, Journal of Public Health Policy 30 (1), 264-285.

OLIVEIRA S., ANDRADE H., VAZ T. (2011), The cooling effect of green spaces as a contribution to the mitigation of urban heat: $A$ case study of Lisbon, Building and Environment 46 (11), 2186-2194.

PANDURO T. E., JENSEN C. U., HEDEMARK LUNDHEDE T., VON GRAEVENITZ K., JELLESMARK THORSENAB B. (2018), Eliciting preferences for urban parks, Regional Science and Urban Economics 73, 127-142.

PANDURO T. E., LAUSTED VEIE K. (2013), Classification and valuation of urban green spaces - A hedonic house price valuation, Landscape and Urban Planning 120, 119-128.

PRETTY J., PEACOCK J., SELLENS M., GRIFFIN M. (2005), The mental and physical health outcomes of green exercise, International Journal of Environmental Health Research 15 (5), 319-337.

SHIMOMURA Y., MASUDA N., ABE D., YAMAMOTO S., SUZUKI K. (1995), Study on residents' behavior of block park in neighborhood, Journal of the Japanese Institute of Landscape Architecture 58 (5), 217-220.

SICK NIELSEN T., BRUUN HANSEN K. (2007), Do green areas affect health? Results 
from a Danish survey on the use of green areas and health indicators, Health \& Place 13 (4), 839-850.

SONG C., IKEI H., IGARASHI M., TAKAGAKI M., MIYAZAKI Y. (2015), Physiological and psychological effects of a walk in urban parks in fall, International Journal of Environmental Research and Public Health 12 (11), 14216-14228.

SPRONKEN-SMITH R. A., OKE T. R. (1998), The thermal regime of urban parks in two cities with different summer climates, International Journal of Remote Sensing 19 (11), 20852104.

SUTTON P. C., ANDERSON S. J. (2016), Holistic valuation of urban ecosystem services in New York City's Central Park, Ecosystem Services 19, 87-91.

TAJIMA K. (2003), New Estimates of the Demand for Urban Green Space: Implications for Valuing the Environmental Benefits of Boston's Big Dig Project, Journal of Urban Affairs 25 (5), 641-655

TAKANO T., NAKAMURA K., WATANABE M. (2002), Urban residential environments and senior citizens' longevity in megacity areas: the importance of walkable green spaces, Journal of Epidemiology \& Community Health 56 (12), 913-918.

TYRVÄINEN L., OJALA A., KORPELA K., LANKI T., TSUNETSUGU Y., KAGAWA T. (2014), The influence of urban green environments on stress relief measures: $A$ field experiment, Journal of Environmental Psychology 38, 1-9.

TZOULAS K., KORPELA K., VENN S., YLI-PELKONEN V., KAŹMIERCZAK A., NIEMELA J., JAMES P. (2007), Promoting ecosystem and human health in urban areas using green infrastructure: A literature review, Landscape and Urban Planning 81 (3), 167-178.

UCHIYAMA K. (2007), $\mathrm{CO}_{2}$ Emission and the Environmental Kuznets Curve: Evidence from Dynamic Panel Data Estimation, Economics Today 27 (3).

VIDRIH B., MEDVED S. (2013), Multiparametric model of urban park cooling island, Urban Forestry \& Urban Greening 12 (2), 220-229. DC.

WALKER C. (2004), The public value of urban parks, The Urban Institute, Washington,

WOLCH J., JERRETT M., REYNOLDS K., MCCONNELL R., CHANGE R., DAHMANN N., BRADY K., GILLILAND F., SU J. G., BERHANE K. (2011), Childhood obesity and proximity to urban parks and recreational resources: A longitudinal cohort study, Health \& Place 17 (1), 207-214.

WOLCH J. R., BYRNE J., NEWELL J. P. (2014), Urban green space, public health, and environmental justice: The challenge of making cities 'just green enough', Landscape and Urban Planning 125, 234-244.

ZHU C., WANG Y., REN W., LUO I., YIN Y., XIE W., LIU W. (2016), The Planning of Green Spaces to Prevent and Avoid Urban Disasters in Dujiangyan, International Journal of Simulation - System, Science \& Technology 17 (46), 27.1-27.6.

Initial submission: 22.01.2019

Revised submission: 25.04.2019

Final acceptance: 30.05 .2019

Correspondence: Hirao School of Management, Konan University, 8-33

Takamatsucho, Nishinomiya, Hyōgo 663-8204, Japan.

Email: ken_japan51@hotmail.com 